\title{
The regulation revolution: the future is here
}

\author{
Trevor Jackson deputy editor, The BMJ
}

What do patients, the public, and employers expect from doctors? Who should set the professional standards? And how should we judge whether doctors are meeting those standards? The fact that questions such as these get asked so often shows how much things have changed since the days when regulation was run by doctors for doctors and when most doctors were left alone from the day they qualified to the day they retired, as Kieran Walshe and Julian Archer say in The BMJ this week (BMJ 2014;349:g5744, doi:10.1136/bmj.g5744).

Instead we are moving to a world in which "state sponsored regulation is run by key stakeholders-including employers, the public, and the profession - and is primarily concerned with the safety and quality of care." Key features of this new regulatory landscape are the overseeing of doctors' performance throughout their professional life and the use of data to understand variations in practice and to spot potential concerns about harm or safety. A 190 page bill representing the most radical and comprehensive reform of health profession regulation ever proposed has been shelved for the current parliament, but Walshe and Archer are confident that it is likely to make it to the statute books eventually, "not least because . . the reforms are much needed."

The Bristol inquiry of 2001, the Shipman inquiry of 2004, and the two more recent inquiries into Mid Staffordshire were obvious triggers for proposed regulatory reform. But progress has been slow, and Walshe and Archer are concerned that doctors may take some convincing, when they should "take an active role in shaping the future of medical regulation in the interests of patients and the public."

It's more than a year now since an editorial in The $B M J$ called for the patient revolution to begin (BMJ 2013;346:f2614, doi:10. 1136/bmj.f2614). This week Tessa Richards, one of the authors of that editorial, describes a visit to a Dutch hospital where the patient revolution is well and truly under way $(B M J$ 2014;349:g5765, doi:10.1136/bmj.g5765). In 2006 Radboud University Medical Centre in Nijmegen hit the headlines for "scandalously" poor results for cardiac surgery, similar to the scandal at the Bristol Royal Infirmary. Since then, a range of quality improvement and other innovative changes have transformed it into a model of patient participation. The hospital even has its own chief listening officer, Corine Jansen, who points to studies showing that the average doctor interrupts the patient after 18-23 seconds. Jansen explains that she advises doctors to spend the first two minutes of each new consultation listening. "That's how long it takes the average patient to articulate their problems and feel the doctor understands and is on their side. These are essential prerequisites of trust; they take the doctor-patient relationship to a mutually beneficial level and open the gate to shared decision making."

Shared decision making lies at the heart of much of the work of Angela Coulter, the subject of BMJ Confidential this week (BMJ 2014;349:g5743, doi:10.1136/bmj.g5743) and one of the pioneers of patient partnership. For eight years Coulter was chief executive of Picker Institute Europe, which advocates patient centred care. What personal ambition does she still have? "To persuade doctors that patients should be given sufficient information to let them participate in decisions about their care-and that not doing so causes them harm."

Cite this as: BMJ 2014;349:95847

๑ BMJ Publishing Group Ltd 2014 